\title{
STANDARISASI PARAMETER NON SPESIFIK EKSTRAK ETANOL DAUN PEGAGAN (Centella asiatica L.) DI DUA TEMPAT TUMBUH
}

\author{
Aulia Rahmaniati M*, Maria Ulfah, Dewi Andini Kunti Mulangsari \\ Fakultas Farmasi, Universitas Wahid Hasyim \\ Jl. Menoreh Tengah X/ 22 Sampangan Semarang \\ *E-mail : auliarahmaniati69@gmail.com
}

\begin{abstract}
Abstrak
Pegagan leaf (Centella asiatica L.) is one of the potential medicinal plants that are often used for the treatment of analgesics, anti-inflammatory and hepatoprotector. Because of the many benefits of leaf pegagan it is necessary to standardize the extracts to ensure the quality associated with the substance of identity, and the composition of the chemical content whose specifications are contained in the monograph as the quality requirements listed in Materia Medika Indonesia.

This research is an experimental research. Samples in this study were obtained from Tawangmangu and Kediri then extract using maceration method with $96 \%$ ethanol solvent. Standardization of non-specific parameters of ethanol extract of bay leaf includes determination of moisture content, total ash content, acid unsaturated ash content, drying shrinkage, specific gravity and heavy metal contamination ( $\mathrm{Pb}, \mathrm{As}$ and $\mathrm{Hg}$ ). The data of the research results are compared with the standard that has been set in the book of Indonesian Herbal Pharmacopoeia and the Book of Standardization of Natural Medicinal Material.

The result of non-specific test of extract ethanol extract of gotu kola leaf from Tawangmangu obtained by water content $4,689 \% \pm 2,165 \%$, total ash content $3,12 \% \pm 1,76 \%$, acid soluble ash content 0,97\% $\pm 0,87 \%$, weight Type of $1.631 \mathrm{~g} / \mathrm{mL} \pm 1.277 \mathrm{~g} / \mathrm{mL}$, shrinkage dried $11.26 \% \pm 3.355 \%$ and heavy metal contaminants $0.27 \pm 0.519 \mathrm{mg} / \mathrm{kg}$ extract, As $<0.005 \mu \mathrm{g} / \mathrm{mL}, \mathrm{Hg}<0.001 \mathrm{mg} / \mathrm{kg}$ extract. While the result of ethanol extract of pegagan leaf from Kediri is moisture content $6,197 \% \pm 2,489 \%$, total ash content 4,42\% $\pm 2,10 \%$, ash acid unsaturated level $0,97 \% \pm 0,98 \%$, weight of type $1,630 \mathrm{~g} / \mathrm{ML} \pm 1,275 \mathrm{~g} / \mathrm{mL}$, shrinkage

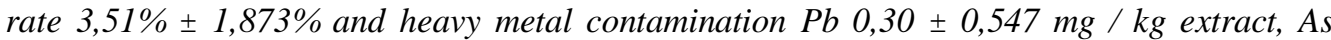
$<0,005 \mu \mathrm{g} / \mathrm{mL}, \mathrm{Hg} 0,001 \mathrm{mg} / \mathrm{kg}$ extract. Based on these results both extracts have met the standard of non-specific parameters but the parameter content of acid soluble ash content of ethanol extract of pegagan leaf from both Tawangmangu and Kediri and drying dried from Tawangmangu does not meet the standard requirements of non-specific parameters.
\end{abstract}

Keywords: ethanol extract of gotu kola leaf, non specific parameter, Standardization.

\section{PENDAHULUAN}

Pengembangan obat tradisional juga didukung oleh Peraturan Menteri Kesehatan Republik Indonesia No. 88 Tahun 2013 tentang Fitofarmaka, yang berarti diperlukan adanya pengendalian mutu simplisia yang akan digunakan untuk bahan baku obat atau sediaan galenik. Salah satu cara untuk mengendalikan mutu simplisia yaitu dengan melakukan standarisasi simplisia. Standarisasi diperlukan agar dapat diperoleh bahan baku yang seragam yang akhirnya dapat menjamin efek farmakologi tanaman tersebut dan untuk menjamin keamanan dan stabilitas ekstrak (Depkes RI., 2006).

Pegagan (Centella asiatica L.) telah lama dimanfaatkan sebagai obat tradisional baik dalam bentuk bahan segar, kering maupun dalam bentuk ramuan. Tanaman ini telah terbukti memiliki efek farmakologi yang telah terbukti dari beberapa penelitian, di Australia pegagan telah banyak dimanfaatkan sebagai obat untuk penyembuh luka, radang, reumatik, asma, wasir, tuberculosis, lepra, disentri, demam dan penambah selera makan (Besung, 2009), analgesik, anti inflamasi dan hepatoprotektor (Bermawie dkk., 2008).

Standarisasi ekstrak etanol daun pegagan mencangkup parameter spesifik dan non spesifik (Depkes RI, 2000). Penentuan parameter non spesifik ekstrak yaitu penentuan aspek kimia, mikrobiologi dan fisik yang akan mempengaruhi keamanan konsumen dan stabilitas (Saifudin dkk, 2011). Penelitian ini hanya dilakukan pada parameter non spesifik karena peneliti ingin melihat perbedaan mutu daun pegagan berdasarkan variasi tempat tumbuh. 
Penelitian standarisasi pada tanaman pernah dilakukan seperti pada Standarisasi Ekstrak Etanol Tanaman Katumpang air (Peperomia pellucida L. Kunth) dari Tiga Tempat Tumbuh yang Berbeda yaitu Tangerang selatan, Bogor, Yogyakarta. Menunjukkan hasil yang memenuhi persyaratan mutu yang tertera pada monografi simplisia (Irsyad., 2013).

Dari uraian di atas, maka perlu dilakukan standarisasi pada daun pegagan (Centella asiatica L.) sehingga dapat menetapkan keamanan mutu dan kualitas bahan-bahan baku ekstrak yang digunakan dalam menunjang kesehatan. Pengujian standarisasi dilakukan pada daun pegagan dengan menggunakan metode maserasi menggunakan pelarut etanol 96\%. Etanol memiliki kemampuan untuk menyari dengan polaritas yang tinggi mulai dari senyawa non polar sampai polar (Saifudin dkk., 2011).

Hasil penelitian diharapkan dapat memberi informasi beberapa nilai parameter mutu simplisia dari ekstrak etanol daun Pegagan (Centella asiatica L.) sehingga dapat digunakan sebagai acuan dalam penelitian berikutnya maupun penggunaan dalam pengobatan.

\section{METODOLOGI PENELITIAN}

\section{Alat Penelitian dan Bahan Penelitian}

Peralatan yang digunakan pada penelitian ini adalah blender, oven, timbangan analitik, alat maserasi, rotary evaporator, glassware, piknometer, Atomic Absorbtion Spectrofotometry (AAS), gravimetry, kertassaring, kertas saring bebas abu, krus silikat, tanur, destilat dan heating mantel.

Bahan-bahan yang digunakan pada penelitian ini adalah daun pegagan dari Kabupaten Kediri dan Kabupaten Tawangmangu, etanol 96\%, aquadest, asam perklorat $\left(\mathrm{HCLO}_{4}\right)$, asam nitrat $\left(\mathrm{HNO}_{3}\right)$ pekat, toluene $\mathrm{P}$, asam sulfat $\left(\mathrm{H}_{2} \mathrm{SO}_{4}\right)$ encer dan air panas.

\section{Prosedur Penelitian \\ DeterminasiTanaman}

Daun Pegagan dideterminasi di Laboratorium Ekologi dan Biosistematik Jurusan Biologi, Fakultas Matematika dan Ilmu Pengetahuan Alam, Universitas Diponegoro. Determinasi dilakukan dengan menggunakan kunci determinasi yang terdapat pada buku Flora of Java.

\section{Pembuatan Serbuk Simplisia}

Daun Pegagan yang diperoleh dari Kabupaten Tawangmangu dan Kabupaten Kediri dipisahkan berdasarkan lokasi pengambilan agar masing-masing simplisia tidak tercampur. Daun pegagan dicuci dengan aquadest mengalir, untuk menghilangkan tanah dan pengotor lainnya yang masih menempel pada bahan yang sudah disortasi basah. Kemudian dikeringkan dengan oven pada suhu $50^{\circ} \mathrm{C}$ sampai kering. Simplisia kering dihaluskan dengan menggunakan blender hingga menjadi serbuk dengan ukuran derajat kehalusan yang sesuai, lalu diukur kadar airnya dengan alat moisture balance. Setelah itu disimpan dalam wadah kering tertutup rapat dalam ruangan terlindung dari cahaya matahari.

\section{Pembuatan ekstrak}

Serbuk daun Pegagan di ekstraksi dengan menggunakan metode maserasi dengan pelarut etanol 96\% selama 7 hari. Filtrat kemudian di evaporasi untuk mendapatkan ekstrak kental etanol 70\%. Ekstrak kental yang didapatakan digunakan untuk dilakukan uji parameter non spesifik.

\section{Penentuan Parameter Non Spesifik Kadar air}

Penentuan kadar air menggunakan cara destilasi toluen. Toluen dijenuhkan dengan air terlebih dahulu, setelah dikocok di diamkan selama 24 jam. Kedua lapisan air dan toluene akan memisah, lapisan air dibuang. Kemudian ekstrak sebanyak 2,5 gram, ditimbang seksama dan dimasukkan ke dalam labu. Lalu dimasukkan lebih kurang $100 \mathrm{ml}$ toluen $\mathrm{P}$ ke dalam labu dan alat dihubungkan. Setelah lapisan air dan toluene memisah sempurna, volume air dibaca dan dihitung kadar air dalam persen (Depkes RI, 2000). Replikasi sebanyak 3

$$
\% \text { KadarAir }=\frac{\text { volume air }(\mathrm{ml})}{\text { bobot sampel }(\mathrm{gram})} \mathbf{X 1 0 0} \%
$$

kali untuk masing-masing ekstrak.

\section{Kadar Abu Total}

Satu gram ekstrak ditimbang seksama lalu dimasukkan dalam krus silikat yang sebelumnya telah dipijarkan dan ditimbang. Kemudian abu dipijar menggunakan tanur secara perlahan-lahan (dengan cara suhu dinaikkan secara bertahap hingga $600 \pm$ 
$25^{\circ}$ Cselama 5 jam hingga arang habis (Depkes RI, 2000). Replikasi sebanyak 3 kali untuk masing-masing ekstrak. Dihitung menggunakan rumus dibawah ini.

$\%$ Kadar Abu Total $=\frac{W 2-W 0}{W 1} X 100 \%$

Keterangan :

W0 : bobotcawankosong (g)

W1 :bobotekstrakawal (g)

W2 : bobotcawan + ekstraksetelahdiabukan (g)

\section{Kadar Abu TidakLarut Asam}

Abu yang diperoleh pada penetapan kadar abu dididihkan dengan $25 \mathrm{~mL} \mathrm{H}_{2} \mathrm{SO}_{4}$ encer selama 5 menit, dikumpulkan bagian yang tidak larut asam dan disaring dengan kertas saring bebas abu, residunya dibilas dengan air panas. Kemudian dimasukkan kembali dalam krus silikat yang sama. Abu dipijar menggunakan tanur secara perlahanlahan (dengan cara suhu dinaikkan secara bertahap hingga $600 \pm 25^{\circ} \mathrm{C}$ selama 5 jam atau hingga arang habis (Depkes RI, 2000).

Replikasi sebanyak 3 kali. Ditimbang hingga bobot tetap kemudian dihitung dengan rumus dibawah ini.

\begin{tabular}{|l} 
\%Kadar Abu Tidak Larut Asam= \\
$\frac{W 2-(c \times 0,0076)-W 0}{W 1} \times \mathbf{1 0 0} \%$
\end{tabular}

Keterangan :

W0 : bobotcawankosong (g)

W1 : bobotekstrakawal (g)

W2 : bobotcawan + abu yang

tidaklarutasam $(\mathrm{g})$

C : bobotkertassaring $(\mathrm{g})$

\section{Kadar BobotJenis}

Piknometer yang sudah kering dan bersih ditimbang. Kemudian dikalibrasi dengan menetapkan bobot piknometer dan bobot air yang baru dididihkan pada suhu $25^{\circ} \mathrm{C}$ kemudian ditimbang. Suhu ekstrak cair diatur hingga $\pm 20^{\circ} \mathrm{C}$, lalu dimasukkan dalam piknometer. Dibuang kelebihan ekstrak, atur suhu piknometer yang telah isi hingga suhu $25^{\circ} \mathrm{C}$ kemudian ditimbang (Depkes RI, 2000). Replikasi sebanyak 3 kali untuk masing-masing ekstrak.

Hitung bobot jenis dengan menggunakan rumus sebagai berikut :

$$
d=\frac{W 2-W_{0}}{W 1-w_{0}} \times \text { bj air }
$$

Keterangan :

$$
\text { bobotjenis }
$$

W0 : bobotpiknometerkosong

W1 : bobotpiknometer + air

W2 : bobotpiknometer + ekstrak

\section{Kadar Susut Pengeringan}

Ekstrak sebanyak 1 gram ditimbang dan dimasukkan dalam botol timbang dangkal bertutup yang sebelumnya telah dipanaskan pada suhu $105^{\circ} \mathrm{C}$ selama 30 menit dan telah ditara. Kemudian dimasukkan kedalam Halogen Moisture Analyzer pada suhu $105^{\circ} \mathrm{C}$ selama 30 menit atau hingga bobot tetap (Depkes RI, 2000). Dilakukan replikasi sebanyak 3 kali dan catat hasil dalam bentuk persen.

\section{Kadar CemaranLogamBerat $(\mathrm{Pb}, \mathrm{Hg}$ dan As)}

Penetapan cemaran logam berat menggunakan alat Atomic Absoption Spectrophotometer (ASS). Penetapan kadar ketiga logam berat dilakukan dengan cara destruksi basah. Ekstrak ditimbang 1 gram dan ditambahkan $10 \mathrm{~mL} \mathrm{HNO}_{3}$ pekat, panaskan dengan heating mantel hingga kering atau kental. Ekstrak yang kental dan dingin ditambahkan aquadest $10 \mathrm{~mL}$ dan asam perklorat $5 \mathrm{~mL}$, dipanaskan hingga kental lalu disaring ke labu ukur $50 \mathrm{~mL}$.

Sampel diukur dengan alat Atomic Absorption Spectophotometer. Maksimal residu $\mathrm{Pb}$ tidak boleh melebihi $10 \mathrm{mg} / \mathrm{kg}$ ekstrak, residu $\mathrm{Hg}$ tidak melebihi $0,001 \mathrm{mg} / \mathrm{kg}$ ekstrak dan As tidak melebihi $0,005 \mathrm{mg} / \mathrm{kg}$ ekstrak(Saifudin dkk., 2011).

\section{HASIL DAN PEMBAHASAN}

Daun pegagan yang digunakan pada penelitian ini berasal dari Tawangmangu dan Kediri. Sebelum dilakukan uji terlebih dahulu sampel dideterminasi. Determinasi tanaman dilakukan dengan cara mencocokkan morfologi tanaman dengan kata kunci pada buku Flora of Java (Backer and Van Den Brink, 1968). Mengacu pada buku tersebut didapatkan hasil bahwa tanaman yang digunakan pada penelitian 
ini benar-benar tanaman pegagan (Centella asiatica L.).

Daun pegagan yang sudah bersih lalu dikeringkan dengan oven pada suhu $50^{\circ} \mathrm{C}$. Pengeringan bertujuan untuk mengurangi kadar air agar simplisia yang didapat tidak mudah rusak dan dapat mencegah pertumbuhan kapang, jamur dan bakteri serta dapat disimpan dalam waktu yang relatif lama. Pengubahan bentuk menjadi serbuk bertujuan untuk meningkatkan luas permukaan bahan baku, karena semakin luas permukaan dapat memperbesar kontak dengan pelarut (Voigt, 1995).

Serbuk daun pegagan diekstraksi menggunakan metode maserasi. Prinsip maserasi adalah pengikatan/pelarutan zat aktif berdasarkan sifat kelarutannya dalam suatu pelarut (like dissolved like). Pelarut yang dipilih adalah etanol 96\%. Etanol memiliki kemampuan untuk menyari dengan polaritas yang lebar mulai dari senyawa nonpolar sampai dengan senyawa polar. Keuntungan pelarut etanol adalah tidak toksik, bersifat netral dan memiliki titik didih rendah.Filtrat yang didapat kemudian dipekatkan dengan menggunakan rotary evaporator hingga diperoleh ekstrak kental. Prinsip rotary evaporator adalah proses pemisahan ekstrak dari cairan penyari dengan pemanasan yang dipercepat oleh putaran dari labu. Suhu disesuaikan dengan titik didih pelarut.

Parameter non spesifik yang ditetapkan dalam penelitian ini meliputi kadar air, kadar abu total, kadar abu tidak larut asam, susut pengeringan, bobot jenis dan cemaran logam berat $(\mathrm{Pb}, \mathrm{Hg}$ dan $\mathrm{As})$. Hasil penetapan parameter non spesifik ekstrak etanol daun pegagan dapat dilihat pada tabel I.

\section{Tabel 1. Parameter non spesifik Ekstrak Etanol pada Pegagan}

\begin{tabular}{|l|l|l|l|}
\hline \multirow{2}{*}{ Parameter non spesifik } & \multicolumn{2}{|c|}{ Hasil } & $\begin{array}{l}\text { Syarat Standar } \\
\text { Parameter } \\
\text { spesifik }\end{array}$ \\
\cline { 2 - 4 } & ngu Tawangma & Kediri & $<10 \%$ \\
\hline Kadar air & 4,689 & 6,197 & $<10 \%$ \\
\hline Kadar abu total & 3,12 & 4,4 & $<16,6 \%$ \\
\hline Kadar abu tidak larut asam & 0,97 & 4,42 & $<0,7 \%$ \\
\hline Bobot jenis & 1,631 & 1,630 & - \\
\hline Susut pengeringan & 11,26 & 3,51 & $<11 \%$ \\
\hline Logam Pb & 0,27 & 0,30 & $<10 \mathrm{mg} / \mathrm{kg}$ \\
\hline Logam $\mathrm{Hg}$ & $<0,001$ & $<0,001$ & $<0,001 \mathrm{mg} / \mathrm{kg}$ \\
\hline Logam As & $<0,005$ & $<0,005$ & $<0,005 \mathrm{mg} / \mathrm{kg}$ \\
\hline
\end{tabular}

Berdasarkan table 1 kadar air kedua ekstrak etanol daun pegagan telah memenuhi syarat. Kadar air yang diperbolehkan adalah $<10 \%$. Perbedaan hasil dari parameter kadar air tersebut dimungkin karena perbedaan lingkungan tumbuh sampel yang digunakan. Beberapa faktor penting dari lingkungan tumbuh diantaranya ketinggian tumbuh, kelembapan udara dan intensitas cahaya mahatari. Ketinggian tempat tumbuh dapat mempengaruhi kondisi tumbuhan secara morfologi maupun fisiologi. Kadar air sangat mempengaruhi pada daya simpan dari suatu bahan pangan. Semakin banyak kadar air yang terkandung, umur simpannya semakin sebentar, karena jika suatu bahan banyak mengandung kadar air, maka kemungkinan adanya mikroba yang tumbuh.
Tabel I menunjukan bahwa ekstrak etanol daun pegagan telah memenuhi syarat standar kadar abu total menurut parameter standar yang berlaku adalah tidak lebih dari 16,6\% (Depkes RI, 2008) Kadar abu total dari Kediri memiliki kadar yang lebih tinggi dibandingkan dengan kadar abu dari Tawangmangu, hal ini dapat disebabkan adanya pengaruh dari tempat tumbuh, proses pasca panen dan preparasi akhir seperti pengeringan. Proses pemanenan dan preparasi simplisia merupakan proses yang dapat menentukan mutu dari simplisia.

Menurut Farmakope Herbal kadar abu tidak larut asam tidak boleh lebih dari $0,7 \%$. Dari hasil yang didapat menunjukan bahwa ekstrak etanol daun pegagan tidak memenuhi persyaratan standar umum Farmakope Herbal Indonesia (2008). Besarnya kadar abu tidak 
larut asam, mungkin disebabkan oleh adanya pasir atau pengotor lain yang masih ada, kemungkinan karena proses pencucian yang tidak bersih. Kadar abu tidak larut asam adalah satu syarat dalam menentukan tingkat kebersihan dalam proses pengolahan suatu produk.

Hasil pengujian susut pengeringan pada tabel di atas ekstrak daun pegagan dari Tawangmangu lebih tinggi dibandingkan dari Kediri, hal ini dipengaruhi oleh kadar air. Batas maksimum susut pengeringan menurut Farmakope Herbal tidak lebih dari $11 \%$. Dengan mengetahui susut pengeringan dapat memberikan batasan maksimal tentang besarnya senyawa yang hilang pada proses pengeringan (Depkes RI, 2000).

Bobot jenis diartikan sebagai perbandingan kerapatan suatu zat terhadap kerapatan air dengan nilai masa persatuan volume. Penentuan bobot jenis bertujuan untuk memberi batasan tentang besarnya massa persatuan volume yang merupakan parameter khusus ekstrak cair sampai menjadi ekstrak kental yang masih dapat dituang, bobot jenis juga terkait dengan kemurnian ekstrak dari kontaminasi (Depkes RI, 2000).

Dari hasil uji logam diatas menunjukan hasil yang tidak melebihi batas yang telah ditetapkan pada parameter ekstrak. Penetapan kadar logam berat Timbal (Pb), Arsen (As), Merkuri ( $\mathrm{Hg}$ ) pada ekstrak etanol daun pegagan bertujuan untuk menjamin ekstrak tidak mengandung logam melebihi batas yang ditetapkan karena bersifat toksik bagi tubuh. Batas maksimal residu $\mathrm{Pb}$ tidak boleh melebihi $10 \mathrm{mg} / \mathrm{kg}$ ekstrak, residu As tidak melebihi 5 $\mu \mathrm{g} / \mathrm{kg}$ dan residu $\mathrm{Hg}$ tidak boleh lebih dari 1 $\mathrm{mg} / \mathrm{kg}$.

\section{KESIMPULAN DAN SARAN \\ Kesimpulan}

a. Penetapan parameter non spesifik ekstrak etanol daun pegagan (Centella asiatica L.) dari Tawangmangu dan Kediri pada parameter kadar air, kadar abu tidak larut asam, bobot jenis, dan cemaran logam berat memenuhi persyaratan berdasarkan Parameter Standar Umum Ekstrak Tumbuhan Obat.

b. Penetapan parameter non spesifik ekstrak etanol daun pegagan (Centella asiatica L.) dari Tawangmangu dan Kediri pada kadar abu tidak larut asam dan parameter susut pengeringan ekstrak etanol daun pegagan
(Centella asiatica L.) dari Tawangmangu tidak memenuhi persyaratan berdasarkan Parameter Standar Umum Ekstrak Tumbuhan Obat.

\section{Saran}

a. Perlu dilakukan penelitian mengenai parameter spesifik ekstrak etanol daun pegagan untuk menjamin kandungan senyawa aktif dari daun pegagan.

b. Proses pencucian perlu dilakukan secara hati-hati dan teliti karena daun pegagan mudah sekali sobek dan untuk menghindari adanya pengotor yang masih menempel pada daun pegagan. Pengeringan dilakukan secara merata untuk menghindari tingginya hasil kadar air dan susut pengeringan.

\section{DAFTAR PUSTAKA}

Besung, K., N., 2009, Pegagan (Centella asiatica) Sebagai Pencegah Infeksi Pada Ternak, Buletin Veteran Udayana, ISSN : 2085-2495, 1 (2) : 61-67.

Bermawie, N., Susi, P., dan Mardiana, 2008, Keragaman Sifat Morfologi Hasil dan Mutu Plasma Nutfah Pegagan (Centella asiatica (L.) Urban.), Bul.Littro. XIX (1) : 1-17.

DepKes RI., 2000, Parameter Standar Umum Ekstrak Tumbuhan Obat, Direktorat Jendral Pengawasan Obat dan Makanan, Jakarta, 10-11.

DepKes RI., 2006, Monografi Ekstrak Tumbuhan Obat Indonesia, Departemen Kesehatan Republik Indonesia, Jakarta, 2, 124.

Depkes RI., 2008, Farmakope Herbal Indonesia, Jilid I, Departemen Kesehatan Republik Indonesia, Jakarta, 110-114.

Irsyad, M., 2013, Standarisasi Ekstrak Etanol Tanaman Katumpang Air (Pepeomia pellucid L. Kunth), Skripsi, Universitas Islam Negri (UIN) Syarif Hidayatullah, Jakarta.

Saifudin, A., Rahayu., dan Teruna, 2011, Standardisasi Bahan Obat Alam, Graha Ilmu, Yogyakarta.

Voigt, R., 1995, Buku Pelajaran Teknologi Farmasi, diterjemahkan oleh Soendani N. S., UGM Press, Yogyakarta, 561. 